This is an electronic reprint of the original article. This reprint may differ from the original in pagination and typographic detail.

Author(s): Portegijs, Erja; Rantanen, Taina; Kallinen, Mauri; Heinonen, Ari; Alén, Markku; Kiviranta, Ilkka; Sipilä, Sarianna

Title: $\quad$ Lower-limb pain, disease and injury burden as determinants of muscle strength deficit after hip fracture

Year: $\quad 2009$

Version:

Please cite the original version:

Portegijs, E., Rantanen, T., Kallinen, M., Heinonen, A., Alén, M., Kiviranta, I., \& Sipilä, S. (2009). Lower-limb pain, disease and injury burden as determinants of muscle strength deficit after hip fracture. The Journal of Bone and Joint Surgery, 91, 17201728. https://doi.org/10.2106/jbjs.g.01675

All material supplied via JYX is protected by copyright and other intellectual property rights, and duplication or sale of all or part of any of the repository collections is not permitted, except that material may be duplicated by you for your research use or educational purposes in electronic or print form. You must obtain permission for any other use. Electronic or print copies may not be offered, whether for sale or otherwise to anyone who is not an authorised user. 


\title{
Lower-Limb Pain, Disease, and Injury Burden as Determinants of Muscle Strength Deficit After Hip Fracture
}

\author{
By Erja Portegijs, PhD, Taina Rantanen, PhD, Mauri Kallinen, MD, PhD, Ari Heinonen, PhD, \\ Markku Alen, MD, PhD, Ilkka Kiviranta, MD, PhD, and Sarianna Sipilä, $\mathrm{PhD}$ \\ Investigation performed at the University of Jyväskylä and the Central Finland Health Care District, Jyväskylä, Finland
}

\begin{abstract}
Background: Hip fracture may result in an asymmetrical lower-limb strength deficit. The deficit may be related to the trauma, surgical treatment, pain, or disuse of the fractured limb. However, disease and injury burden or musculoskeletal pain in the other limb may reduce muscle strength on that side, reducing the asymmetrical deficit. The aim of our study was to explore the asymmetrical strength deficit and to determine the potential underlying factors in patients from six months to seven years after a hip fracture.
\end{abstract}

Methods: The asymmetrical deficit was calculated ([fractured limb/sum of both lower limbs] x 100\%) for isometric knee extension torque, rate of force development during isometric testing, and leg extension power. The asymmetrical measures for lower-limb muscle mass (fractured limb - nonfractured limb), and that of lower-limb pain and disease and injury burden (nonfractured limb - fractured limb), were calculated.

Results: Half of the participants had no consistent asymmetrical deficit on the fractured side. Regression analyses showed that asymmetrical measures of lower-limb pain, muscle mass, and disease and injury burden predicted asymmetrical deficit in knee extension torque $\left(R^{2}=0.43\right)$ and in the rate of force development $\left(R^{2}=0.36\right)$. More intense pain and disease and injury burden affecting the nonfractured limb and smaller muscle mass relative to the fractured limb were associated with a smaller asymmetrical deficit.

Conclusions: Following a hip fracture, the prevention of decreases in muscle strength and power as well as a large asymmetrical deficit by the use of targeted pain management and rehabilitation may help to reduce the risk of subsequent mobility limitations and falls.

Level of Evidence: Prognostic Level II. See Instructions to Authors for a complete description of levels of evidence.

$\mathrm{P}$ oor muscle strength and power are risk factors for mobility limitation, falls, and subsequent loss of independence $^{1-3}$. Muscle strength is partly determined by genetic factors ${ }^{4}$, but it is also highly dependent on muscle use $e^{3,5-7}$. Inactivity decreases muscle strength, which often parallels a decrease in muscle mass ${ }^{6,7}$. Pain ${ }^{8-10}$, disease ${ }^{3,10,11}$, and injury ${ }^{12-14}$ have also been associated with a reduction in muscle strength and mass. Pain may lead to the avoidance of activity ${ }^{15}$ and thereby cause a reduction in muscle strength. As muscle power takes into account the rate of force production, it may be less dependent on muscle mass ${ }^{16}$, yet it is influenced by disease, injury, and pain ${ }^{11,17}$, as is muscle strength, although this has not been studied extensively.

Studies in relatively healthy older women have shown that a large asymmetrical deficit in leg extension power is related to mobility limitation ${ }^{18}$ and frequent ${ }^{19}$ and injurious falls ${ }^{20}$. Since certain diseases such as osteoarthritis ${ }^{21,22}$, injury such as hip fracture $^{17,23,24}$, and pain ${ }^{17,21,25}$ may affect only one limb, there may be a local effect on muscle strength and power potentially causing a large asymmetrical deficit between the lower limbs.

Patients with a hip fracture have persistent poor muscle strength and power ${ }^{1,13}$, in the fractured limb especially ${ }^{17,23,24}$. We

Disclosure: In support of their research for or preparation of this work, one or more of the authors received, in any one year, outside funding or grants in excess of $\$ 10,000$ from the Juho Vainio Foundation, Finnish Cultural Foundation, and Ministry of Education. Neither they nor a member of their immediate families received payments or other benefits or a commitment or agreement to provide such benefits from a commercial entity. No commercial entity paid or directed, or agreed to pay or direct, any benefits to any research fund, foundation, division, center, clinical practice, or other charitable or nonprofit organization with which the authors, or a member of their immediate families, are affiliated or associated. 
The Journal of Bone \& Joint Surgery $\cdot$ Jbjs.org Volume 91-A · Number 7 · July 2009
Lower-Limb Pain, Disease, and Injury Burden as Determinants of Muscle Strength Deficit After Hip Fracture explored the asymmetrical deficit in muscle strength and power in patients at six months to seven years after a hip fracture to determine the potential factors underlying the asymmetrical deficit. We hypothesized that an asymmetrical muscle strength and power deficit would be due to more intense pain, higher disease and injury burden, and poorer muscle mass in the limb on the same side. As the prevalence of hip fracture increases with age, comorbidity in both lower limbs is likely, and therefore the fractured side may not always be the weaker side ${ }^{13,26}$.

\section{Materials and Methods}

\section{Study Design and Participants}

7 his study is based on the baseline data of a larger study investigating health, functional ability, and rehabilitation in people with a history of a hip fracture (Current Controlled Trials web site, ISRCTN34271567).

The patient records of the local central hospital were utilized during 2004 and 2005 to recruit men and women between sixty and eighty-five years old who were living in the community and had sustained a femoral neck or intertrochanteric fracture from six months to seven years earlier. A letter describing the study was sent to all 452 patients living in the catchment area of the local health-care district. A total of 193 patients responded, and 132 of them, who had expressed initial interest, were interviewed over the telephone to ensure eligibility. The patients who were unable to move outside the home without assistance from another person or had severe progressive or neurological disease or a lower-limb amputation were excluded. All seventy-nine remaining eligible patients (fifty-four women and twenty-five men) participated in the examinations. The study was approved by the ethics committee of the Central Finland Health Care District, and the subjects gave their written informed consent prior to participating in the study. The patients received routine care following the hip fracture, which entailed physiotherapy during the stay in the hospital or health-care center. At the time of discharge, patients received written instructions on weight-bearing allowance and home exercises. No follow-up visits to a physiotherapist were arranged routinely.

\section{Health Assessment}

A physician and a research nurse performed a thorough clinical examination prior to the laboratory assessments. The physician used self-reported questionnaires, medical records of the local hospital and medical care facilities, and a clinical examination to confirm the presence of previously diagnosed chronic conditions. The number of chronic diseases present for at least three months was calculated as an indicator of comorbidity. The presence of osteoarthritis and fractures was specified for each limb and joint. The use of pain medication prescribed by a physician was transcribed from current prescriptions and was registered as a dichotomous variable (yes or no).

Characteristics of the hip fracture and the operative treatment were collected from the medical records of the orthopaedic department of the hospital. The cause of the hip fractures was a fall at ground level $(66 \%)$ or from a higher level
(17\%) or other causes such as a bicycle or car accident $(18 \%)$. The number of days between the date of the hip fracture and August 1 of the year the strength measurements were made (2004 or 2005) was calculated and used as the variable for time elapsed since the hip fracture. All data were collected within two to five weeks from this date.

Additionally, contraindications for participation in the muscle strength assessment were evaluated by the physician during the clinical examination using the criteria of the American College of Sports Medicine ${ }^{27}$. Contraindications included unstable coronary artery disease, uncontrolled hypertension, recent intracranial hemorrhage, and aneurysm of the abdominal aorta as well as musculoskeletal disorders, which could potentially progress because of testing. In addition, acute conditions such as infections (e.g., acute respiratory or urinary tract infection) were evaluated to ascertain safe participation in the laboratory measurements. Contraindications for the muscle strength assessments were checked for each lower limb separately. In the clinical examination, five participants were found to have contraindications for participation in all strength and power tests for both limbs and one participant had contraindications for both types of tests in one limb. Additionally, seven participants had contraindications for the leg extension power test only, in both limbs.

\section{Lower-Limb Muscle Strength}

Three measures of muscle strength were assessed for both lower limbs: maximal voluntary isometric knee extension torque, the rate of force development over the first $200 \mathrm{~ms}$ of the isometric contraction, and leg extension power. Alternate participants were tested first on the fractured or on the nonfractured side.

Maximal voluntary isometric knee extension force, which does not involve any movement, was assessed in both lower limbs with use of an adjustable dynamometer chair (Good Strength; Metitur, Jyräskylä, Finland). The ankle was attached to a strain-gauge system with the knee angle fixed at $60^{\circ}$ from full extension. The participants were encouraged to extend the knee as vigorously as possible. After two to three practice trials, measurements were performed at least three times until no further improvement occurred. Each contraction was maintained for two to three seconds. The intertrial rest period was thirty seconds. The performance of the highest maximal force was used for analysis. Maximal knee extension torque (in newton-meters $)^{28}$ was used for analysis and was calculated with use of the formula: force in newtons $\times$ (chair lever arm in meters $\times \cos 30^{\circ}$ ). In addition, the maximal rate of force development over the first $200 \mathrm{~ms}$ of the contraction (in newtonmeters per second) was calculated. The test to assess isometric knee extension strength is widely used and is safe in older people $^{5}$. The test-retest precision with a two-week interval is a mean (and standard deviation) of $6 \% \pm 6 \%$ for knee extension force in our laboratory ${ }^{5}$.

Leg extension power (in watts), the product of force and velocity, was measured in both lower limbs with use of the Nottingham power rig $^{29}$. The seat position was adjusted for limb length. The participant was seated with his or her arms 
The Journal of Bone \& Joint Surgery $\cdot$ Jbjs.org Volume 91-A · Number 7 · July 2009
Lower-Limb Pain, Disease, and Injury Burden as Determinants of Muscle Strength Deficit After Hip Fracture folded, and one foot was placed on the pedal attached to a flywheel, while the other foot rested on the floor. After two to three practice trials, participants were asked to push the pedal as hard and fast as possible five to ten times, until no further improvement occurred. The intertrial rest period was at least thirty seconds. The best performance was used for analysis. Because of pain or limitations in range of motion of the knee or hip in the sitting position suggested by the manufacturer, seven patients with a hip fracture were allowed to sit with their backs leaning on the backrest and one patient was seated on a 7-cm-high cushion. The same position was used for both sides, and thus the sitting position did not affect the asymmetrical deficit. The muscle power measurement with the Nottingham power rig has been validated and found to be safe and acceptable among older people ${ }^{29}$. The test-retest precision with a one to two-week interval in our laboratory is a mean of $8 \% \pm 7 \%{ }^{4}$.

In addition to the participants with contraindications for testing as determined in the clinical examination, two participants were not able to have a valid assessment of force and power because of pain or poor cooperation during the assessment. One participant was unable to perform the strength test, and one participant was unable to perform the power test. Additionally, three participants were unable to perform the power test on one side because of pain or limitation in range of motion. If pain occurred after at least one score was obtained, this value was used as maximal performance.

Characteristics of the Lower Limbs and Asymmetrical Deficit For the muscle strength measures (knee extension torque, rate of force development, and leg extension power) assessed for the fractured and the nonfractured limb, the asymmetrical deficit ([fractured limb/sum of both limbs] $\times 100 \%$ ) was calculated. A value of $50 \%$ represents equal strength in both limbs, indicating no asymmetrical deficit. Values of $<50 \%$ indicate poorer strength in the fractured limb.

Pain in the hip and knee of each lower limb during the previous week was determined with use of a visual analogue scale (range, 0 to $100 \mathrm{~mm})^{22}$. The pain scores of the hip and knee of the same limb were summed and used as a pain measure for the respective limb. The difference between the limbs (nonfractured limb - fractured limb) was used as a measure for asymmetrical lower-limb pain in the analyses.

To describe the burden of disease and injury of each lower limb, we summed the number of joints (hip or knee) affected by osteoarthritis and the number of fractures in the upper part of each lower limb. The hip fracture was included in the calculation. The difference between the limbs (nonfractured limb - fractured limb) was used as a measure for asymmetrical lower-limb disease and injury burden.

The muscle mass of each lower limb was estimated with use of a computerized bioimpedance device with eight polar electrodes (BC-418; TANITA, Tokyo, Japan ${ }^{30}$. The algorithm provided by the manufacturer incorporates impedance, age, and body height and provides separate body mass readings for different body segments. The subjects were requested to avoid exercise or sauna within twelve hours of the laboratory mea- surements as well as to refrain from alcohol intake for twentyfour hours. During the measurements, the participants were instructed to stand still on a scale platform with bare feet while holding the handgrips. The difference in muscle mass between the limbs (fractured limb - nonfractured limb) was used as a measure for asymmetrical lower-limb muscle mass.

The asymmetrical measures of lower-limb pain, lowerlimb disease and injury burden, and lower-limb muscle mass were calculated with use of the formulas to obtain positive correlations between the asymmetrical strength deficit and the other asymmetrical measures.

\section{Other Participant Characteristics}

Body height and weight were measured with use of standard protocols in the laboratory. Lean body mass was assessed with use of the bioimpedance device (BC-418; TANITA).

Maximal voluntary isometric handgrip strength of the dominant hand was assessed with use of an adjustable dynamometer chair (Good Strength; Metitur) and was used as an indicator of general strength ${ }^{5}$. In the assessment, the dynamometer was fixed to the arm of the chair with the elbow flexed to $90^{\circ}$. The participants were encouraged to squeeze the handle as hard as possible. The testing protocol was the same as for the isometric knee extension force assessment.

The level of physical activity was assessed by an interview with use of the Yale physical activity questionnaire ${ }^{31}$. The questionnaire includes a physical activity dimension sum index, which is the summation of five weighted subindices. The participants were asked how many times they had performed vigorous physical activity (a weight of 5) and leisure walking (a weight of 4) during the past month and the duration of each physical activity session. The frequency, duration score, and weight of the respective activity were multiplied. Additionally, the participants were asked to estimate the duration of the time spent moving around (a weight of 3), standing (a weight of 2), and sitting (a weight of 1 ) on an average day in the past month. The duration scores were multiplied by the weight of the respective activity.

\section{Statistical Analysis}

Initially, all analyses were performed separately for men and women. Since the results were similar for men and women, only the pooled analyses are reported.

Because of missing values, seven patients who were without any strength measures were not analyzed. Two additional participants were dropped from all analyses of knee extension torque and rate of force development, and eleven participants were dropped from all analyses of leg extension power. In the group analyses, one participant with knee extension torque and rate of force development measures in one limb only and four participants with leg extension power measures in one limb only were included; the limb not measured because of pain or limitation in range of motion was considered to be the weaker limb. Including or excluding these participants did not materially change the results; therefore, the results are reported with all participants included. An 
TABLE I Characteristics of the Hip Fracture Patients

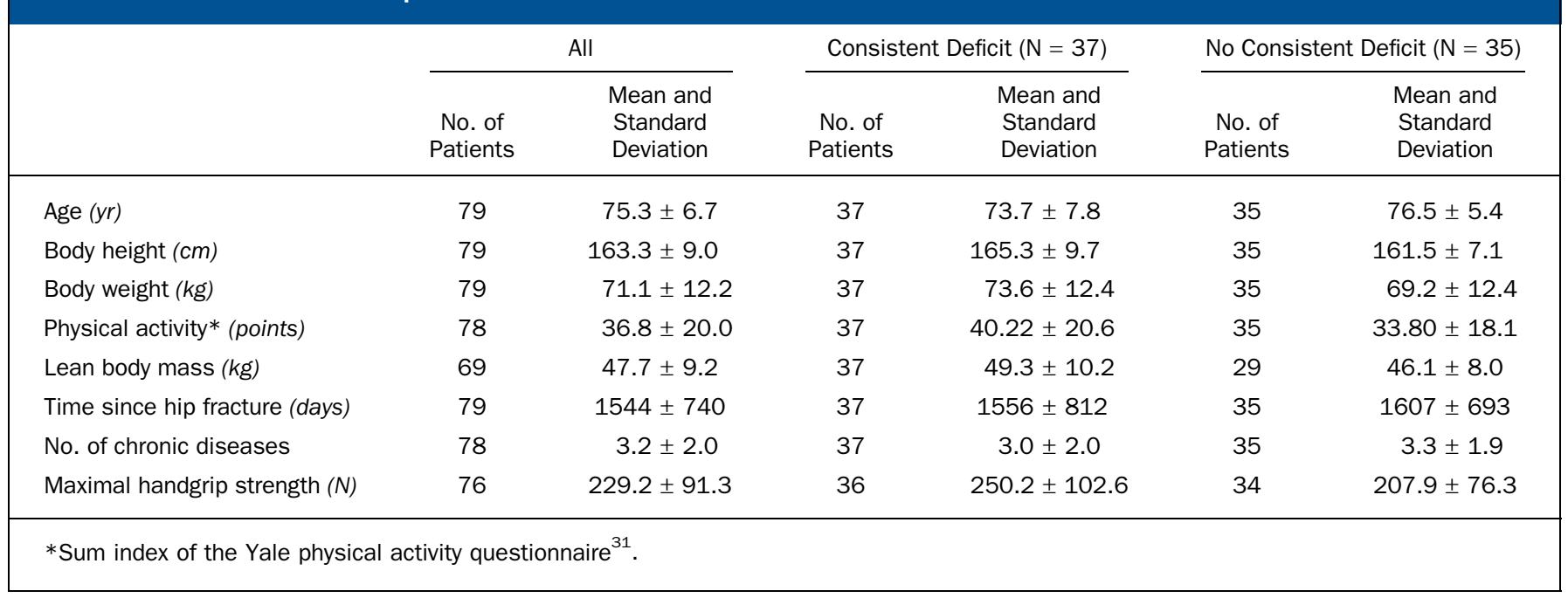

estimation of lower-limb muscle mass was unavailable for ten patients with a hip fracture because of the use of a cardiac pacemaker or technical error.

Differences between the lower limbs were tested with use of the paired-sample $t$ test (parametric variables) or Wilcoxon signed-rank test (nonparametric variables). Multiple linear regression analysis was used to predict asymmetrical deficits in knee extension torque, rate of force development, or leg extension power, respectively, in three separate models. The asymmetrical lower-limb pain, lower-limb disease and injury burden, and lower-limb muscle mass variables were entered at the same time as predictors in the models. The models were also adjusted for potential confounders: age, sex, time since fracture, type of fixation of the hip fracture, and prescribed pain medication. The variables were entered one at a time as the sample size did not allow for simultaneous inclusion.
The patients with a hip fracture were also stratified on the basis of the asymmetrical deficit in knee extension torque, rate of force development, and leg extension power. The participants with a consistent asymmetrical strength deficit in the fractured limb $(<50 \%$ for all measures) were compared with those with either no asymmetrical deficit or a deficit in the nonfractured limb for at least one of the muscle strength measures. Group differences in participant characteristics were tested with use of chi-square tests and independent $t$ tests. The ordinal scale variable for lower-limb disease and injury burden was tested with a Mann-Whitney $U$ test, and, because of a slight distortion in the distribution of the lower-limb pain measure on the nonfractured side, the lower-limb pain measure was tested with the independent $\mathrm{t}$ test and the Mann-Whitney U test. Significance was set at $\mathrm{p}<0.05$.

TABLE II Characteristics of the Fractured and the Nonfractured Lower Limb and the Asymmetrical Measures in All Hip Fracture Patients

\begin{tabular}{|lccccc|}
\hline & $\begin{array}{c}\text { No. of } \\
\text { Patients }\end{array}$ & $\begin{array}{c}\text { Fractured } \\
\text { Limb* }\end{array}$ & $\begin{array}{c}\text { Nonfractured } \\
\text { Limb* }\end{array}$ & $\begin{array}{c}\text { Side Difference } \\
(p \text { value })\end{array}$ & $\begin{array}{c}\text { Asymmetrical } \\
\text { Measure*† }\end{array}$ \\
\hline Knee extension torque $(\mathrm{Nm})$ & 70 & $63.2 \pm 30.5$ & $72.4 \pm 35.5$ & $<0.001 \neq$ & $47.1 \pm 8.4$ \\
Rate of force development $(\mathrm{Nm} / \mathrm{s})$ & 70 & $151.7 \pm 117.8$ & $182.3 \pm 138.4$ & $0.001 \neq$ & $46.3 \pm 13.0$ \\
Leg extension power $(\mathrm{W})$ & 61 & $84.2 \pm 44.3$ & $101.4 \pm 54.4$ & $<0.001 \neq$ & $45.4 \pm 5.5$ \\
Limb muscle mass $(\mathrm{kg})$ & 69 & $7.4 \pm 1.4$ & $7.4 \pm 1.4$ & $0.575 \neq$ & $-0.0 \pm 0.3$ \\
Limb pain $(\mathrm{mm})$ & 79 & $62.6 \pm 58.5$ & $30.9 \pm 44.8$ & $<0.001 \neq \S$ & $-31.8 \pm 50.8$ \\
Limb disease and injury burden\# $(n)$ & 79 & $1(1-2)$ & $0(0-2)$ & $<0.001 \S$ & $-1(-2-1)$ \\
\hline
\end{tabular}

*The values are given as the mean and the standard deviation, except where otherwise noted. †Asymmetrical knee extension torque, rate of force development, and leg extension power were calculated with the formula: (fractured limb/sum of both limbs) $\times 100 \%$. Asymmetrical lower-limb muscle mass was calculated as the difference in muscle mass between the limbs (fractured limb - nonfractured limb). Asymmetrical lower-limb pain and lower-limb disease and injury burden were calculated as the difference between the limbs (nonfractured limb - fractured limb). $\neq$ The difference between the limbs was tested with the paired t test. §The difference between the limbs was tested with the Wilcoxon signed-rank test. \#The values are given as the median with the range in parentheses. 
The Journal of Bone \& JoInt Surgery $\cdot$ JbjS. org Volume 91-A • Number 7 · July 2009
Lower-Limb Pain, Disease, and Injury Burden as Determinants of Muscle Strength Deficit After Hip Fracture

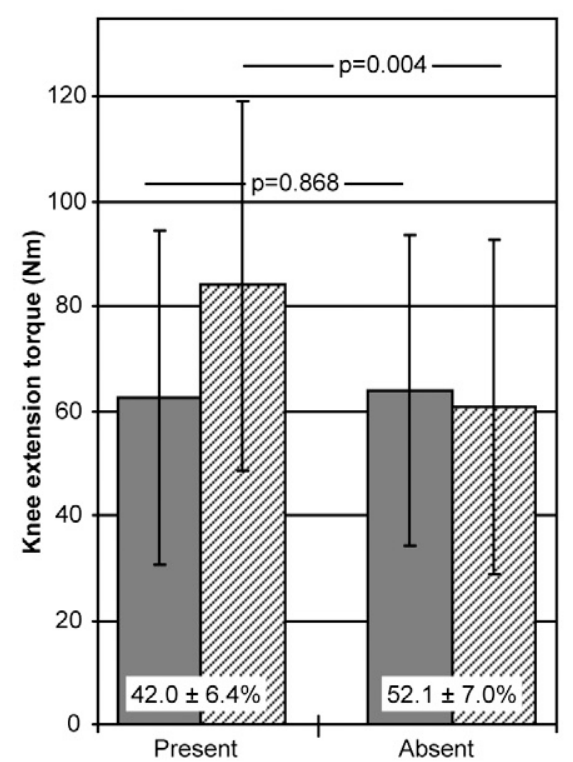

a

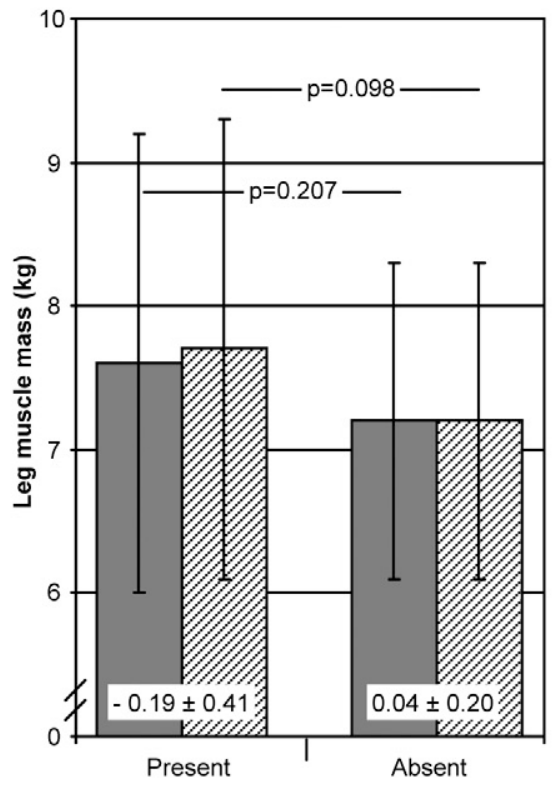

d

Fig. 1

The means and standard deviations of the characteristics of the fractured and the nonfractured limb in participants with the absence or presence of a consistent asymmetrical deficit on the fractured side (the fractured limb was weaker than the nonfractured limb in all muscle strength measures; asymmetrical deficit scores were $<50 \%$ ). Group differences (independent $t$ test) are indicated with horizontal lines. For knee extension torque (a), rate of force development (b), and leg extension power (c), the means and standard deviations of the asymmetrical deficit are noted on the bases of the bars. For lower-limb muscle mass (d) and lower-limb pain (e), the means of the asymmetrical measures are noted similarly.

\section{Source of Funding}

This study was supported by the Juho Vainio Foundation, Finnish Cultural Foundation, and Ministry of Education. The funders had no further interest or involvement in the design, methods, subject recruitment, data collection, and preparation of the manuscript.

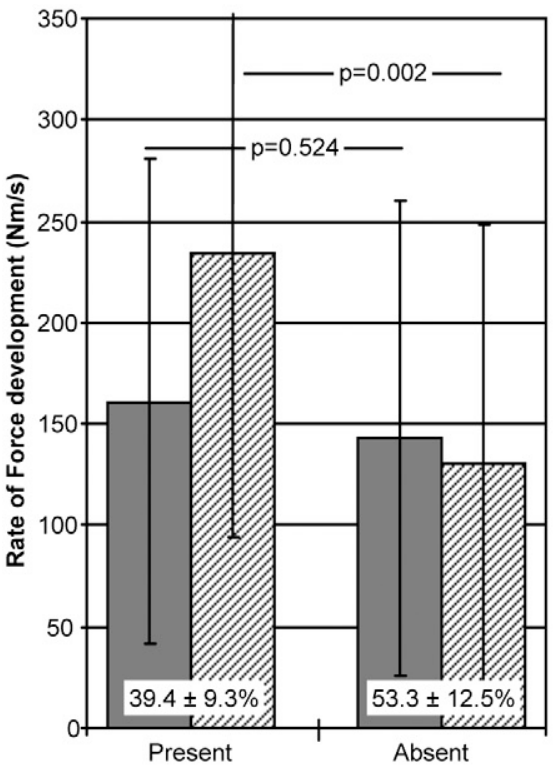

b

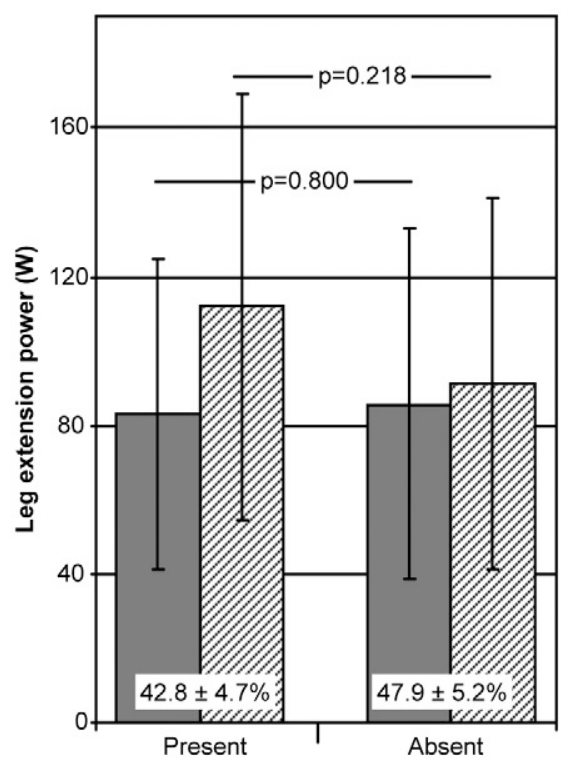

C
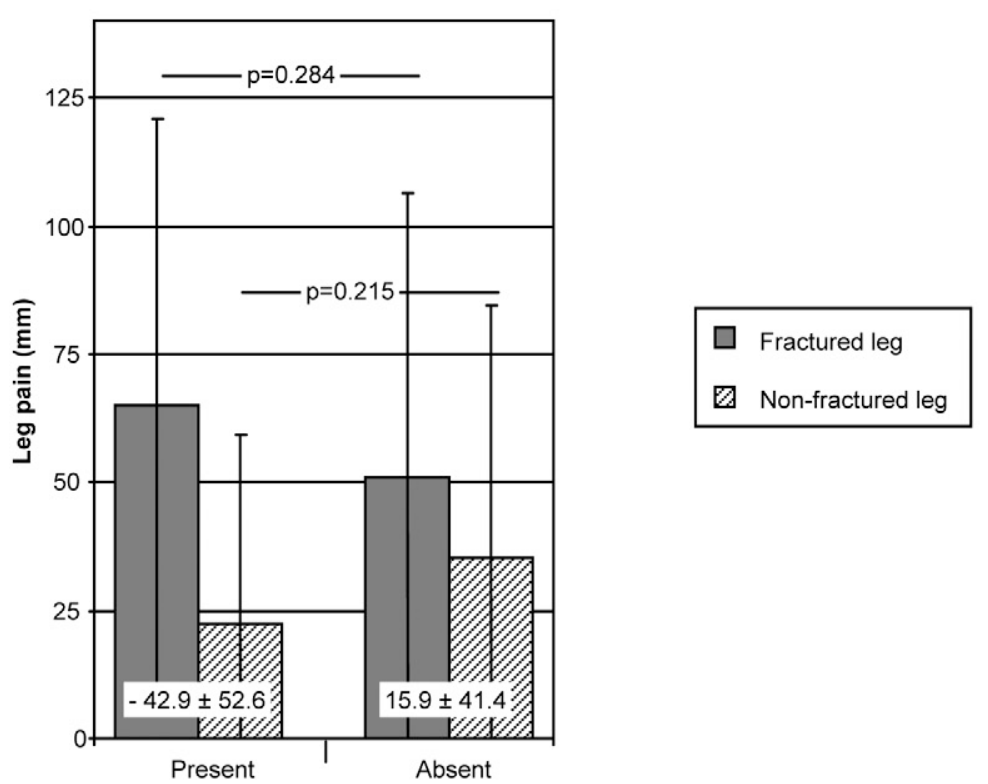

e 


\begin{tabular}{|c|c|c|c|c|c|c|}
\hline & $\mathrm{R}^{2}$ & Beta & P Value & $\mathrm{R}^{2}$ & Beta & P Value \\
\hline Asymmetrical deficit in knee extension torque $(n=64)$ & 0.429 & & $<0.001$ & & & \\
\hline Asymmetrical limb pain & & 0.284 & 0.007 & & & \\
\hline Asymmetrical limb disease and injury burden & & 0.408 & $<0.001$ & & & \\
\hline Asymmetrical deficit in rate of force development $(n=64)$ & 0.362 & & $<0.001$ & & & \\
\hline Asymmetrical limb pain & & 0.259 & 0.019 & & & \\
\hline Asymmetrical limb disease and injury burden & & 0.383 & 0.001 & & & \\
\hline Asymmetrical limb muscle mass & & 0.343 & 0.002 & & & \\
\hline Asymmetrical deficit in leg extensor power $(n=57)$ & 0.158 & & 0.027 & 0.112 & & 0.009 \\
\hline
\end{tabular}

thirty-seven patients (47\%) and with arthroplasty in forty-two patients $(53 \%)$. Twenty-two patients $(28 \%)$ used pain medication prescribed by a physician.

\section{Characteristics of the Lower Limbs and Asymmetrical Deficit} On the average, the fractured limb was significantly weaker and more painful than the nonfractured limb (Table II). Also, the overall disease and injury burden was significantly larger in the fractured than in the nonfractured limb $(p<0.001)$.

Participants with a consistent asymmetrical deficit on the fractured side did not differ from those without one with regard to any of the participant characteristics $(p>0.06)$. The measures of lower-limb muscle strength and mass of the fractured limb were not significantly different between the groups (Fig. 1). However, for the nonfractured limb, the knee extension torque and the rate of force development were significantly lower in the group without a consistent asymmetrical deficit. For leg extension power, the nonfractured limb was not significantly different between the groups. The muscle mass of the nonfractured limb tended to be smaller in the group without a consistent asymmetrical deficit $(\mathrm{p}=0.098)$. Lower-limb pain levels in the fractured and nonfractured limbs were not found to be significantly different between the groups with use of parametric $(\mathrm{p} \geq 0.22)$ (Fig. 1,e) or nonparametric tests $(p>0.19)$. The disease and injury burden of the fractured limb (one to two diseases and/or injuries, including the hip fracture) was not significantly different between the groups $(p=0.66)$. The disease and injury burden in the nonfractured limb was significantly higher $(\mathrm{p}<0.05)$ in those without (zero to two diseases and/or injuries) than in those with (zero to one disease or injury) a consistent asymmetrical deficit.

Predicting an Asymmetrical Deficit in Knee Extension Torque, Rate of Force Development, and Leg Extension Power In the regression analyses, the asymmetrical measures of lowerlimb pain, lower-limb disease and injury burden, and lower- limb muscle mass correlated significantly with the asymmetrical deficit in knee extension torque and rate of force development (Table III). A smaller strength deficit on the fractured side was associated with more intense limb pain and higher disease and injury burden affecting the nonfractured limb relative to the fractured limb. Additionally, a smaller strength deficit on the fractured side was associated with lower muscle mass on the nonfractured side relative to the fractured side. The linear regression models explained $43 \%$ and $36 \%$ of the variation in the asymmetrical deficit in knee extension torque and rate of force development, respectively. Inclusion of potential confounding variables of age, sex, time since fracture, type of surgical fixation, and prescribed pain medication one at a time did not materially change the estimates.

An asymmetrical deficit in leg extension power was only related to the asymmetrical measure of lower-limb pain. A smaller deficit on the fractured side was associated with more intense pain in the nonfractured limb relative to the fractured limb. The regression model including all asymmetrical measures explained $16 \%$ of the variation, while inclusion of only asymmetrical lower-limb pain explained $11 \%$ of the variation in asymmetrical leg extension power deficit. When age was included in the first model only, the significance of the asymmetrical pain as a predictor of an asymmetrical deficit in leg extension power changed to $p=0.06$. Inclusion of the other potential confounding variables did not materially change the estimates in the first or second model.

\section{Discussion}

A fter a hip fracture, muscle strength and power remain, on A the average, lower in the fractured than in the nonfractured limb. Half of the subjects with a history of hip fracture had a consistent asymmetrical deficit on the fractured side an average of four years after the hip fracture. The other half had either no consistent strength deficit or a deficit on the nonfractured side. The strength deficit on the fractured side was likely to be reduced 
The Journal of Bone \& Joint Surgery $\cdot$ Jbjs.org Volume 91-A · Number 7 · July 2009
Lower-Limb Pain, Disease, and Injury Burden as Determinants of Muscle Strength Deficit After Hip Fracture or even reversed in the presence of more intense pain or higher disease and injury burden in the nonfractured limb, resulting in poor muscle strength in both lower limbs. These results stress the importance of treating pain and injuries affecting the lower limbs to prevent decreases in muscle strength and power.

Large asymmetrical deficits in muscle strength and power on the fractured side have been reported after a hip fracture ${ }^{17,23,24}$, even three to thirty-six months after the fracture. This study confirms that, on the average, an asymmetrical deficit on the fractured side is present in subjects who had sustained a hip fracture approximately four years earlier. However, only half of the subjects had a consistent asymmetrical deficit on the fractured side. A smaller asymmetrical deficit on the fractured side may not be an indicator of a better recovery from the hip fracture but, rather, a result of more intense pain and higher disease and injury burden affecting the nonfractured limb. Hip fracture patients with no consistent asymmetrical deficit on the fractured side tended to have poorer muscle strength and power in the nonfractured limb compared with those with a consistent deficit.

The results of this study suggest that lower-limb pain and lower-limb disease and injury burden (in this case, osteoarthritis and fractures) had an independent effect on an asymmetrical deficit in muscle strength. In accordance with our expectations, an asymmetrical deficit in all measures of muscle strength and power was associated with more intense pain in the same limb. A previous study by van Wilgen et al. ${ }^{25}$ indicated that chronic, nonspecific pain in one limb was associated with lower muscle strength in the entire limb, indicating an asymmetrical deficit. We are unaware of studies indicating a similar relationship for muscle power. However, a general association between poor muscle power and musculoskeletal pain has been reported ${ }^{11,17}$. In the present study, asymmetrical deficits in isometric knee extension torque and the rate of force development were also independently associated with higher disease and injury burden in the same limb. It is possible that more severe osteoarthritis and fractures cause larger deficits in limb muscle strength. Unfortunately, we had no data on the severity of the osteoarthritis. However, it is likely that those with more severe osteoarthritis reported higher scores on our pain measure. Although the type of fracture and surgical fixation of the hip fracture did not confound the results of our analyses, the effects of the severity and location of osteoarthritis and fractures affecting the limbs warrant further study.

A decrease in muscle strength may be caused by neural and muscular factors ${ }^{6,16}$. Usually, changes in muscle mass are thought to occur over a long time span. Thus, in this group, long-term changes had taken place since muscle mass was reduced on the same side as the muscle strength deficit. One potential cause of the long-term change may be reduced activity or disuse of the limb $b^{6,713}$. A hip fracture is often associated with a subsequent fear of falling ${ }^{13}$, and knee osteoarthritis as well as pain have been associated with fear of movement and injury or reinjury ${ }^{15,32}$. Fear and pain may lead to a vicious cycle of avoidance of certain activities ${ }^{15}$ and thus to a decrease in muscle strength ${ }^{15,33,34}$. Although decreased muscle mass may mediate the pathway from lower-limb pain or lower-limb disease and injury burden to a muscle strength deficit ${ }^{6}$, this study shows that these factors also have an independent effect on the strength deficit. Pain, disease, and injury may also affect muscle strength and power through neural inhibition ${ }^{10}$.

Three different measures of muscle strength were used in this study, and the results were slightly different for leg extension power. Lower-limb pain, lower-limb disease and injury burden, and lower-limb muscle mass explained an important portion of the variation (36\% to $43 \%$ ) in the asymmetrical deficit in knee extension torque and the rate of force development. However, lower-limb pain was the only factor related to an asymmetrical deficit in leg extension power, explaining $11 \%$ of the variation. Therefore, other factors are likely to play a role in leg extension power. Additionally, an asymmetrical deficit in leg extension power seemed to be present more consistently on the fractured side than did asymmetries in the other strength measurements. This may be due to the different nature of the isometric and power testing that involves rapid movement of a joint with a relatively large range of motion. Pain and neural factors may play a more important role in muscle performance involving articular movement ${ }^{6,16}$.

In relatively healthy older women, a large asymmetrical deficit in muscle power has been associated with mobility limitation $^{18}$ and with frequent ${ }^{19}$ and injurious ${ }^{20}$ falls. Hip fracture patients have markedly lower muscle strength and power in general $^{13,17}$ and a larger asymmetrical deficit ${ }^{17,23,24}$ than do relatively healthy older persons. Preventing decreases in muscle strength and power and the development of an asymmetrical deficit between the lower limbs may therefore be beneficial for mobility. Pain management and rehabilitation are thus very important in the treatment of disease or after an injury affecting the lower $\operatorname{limb}(\mathrm{s})$. Interestingly, it has been suggested that increasing muscle strength and power by resistance training may also reduce pain in osteoarthritis ${ }^{35}$. Supervised progressive resistance training is feasible and effective within a few months in healthy older women ${ }^{28}$, in frail older people ${ }^{36}$, and in clinical populations $^{35}$, even shortly after surgery ${ }^{37}$ or hip fracture ${ }^{38}$. In addition, it may be beneficial for mobility in people with mobility limitation ${ }^{35-39}$ and may therefore be a potentially effective intervention when included in the rehabilitation protocol.

Generalization of the results of this study to all hip fracture patients may be difficult, considering that the participants were relatively healthy and well-functioning because of our inclusion criteria (a maximum age of eighty-five years, the ability to live in the community, and the ability to walk outdoors independently). Despite intensive recruitment, the sample size of the study was relatively small. Selective dropping out of patients with multiple medical problems or pain during the muscle strength assessments is likely to have weakened the relationships. Additional studies with larger sample sizes are needed to confirm the associations. Considering the crosssectional study design, the effects of changes and interventions in unilateral lower-limb pain or muscle strength deficit need further study. Considering that pain in this study was not directly related to the fracture, the associations found may apply 
The Journal of Bone \& Joint Surgery - Jbjs.org VOlume 91-A • Number 7 · July 2009
Lower-Limb Pain, Disease, and Injury Burden as Determinants of Muscle Strength Deficit After Hip Fracture to other groups of (frail) older people with comorbidities in the lower limbs as well.

In conclusion, aging is associated with a reduction in muscle strength, whereas pain, diseases, and injury affecting the limbs accelerate the loss of strength. Six months to seven years after a hip fracture, approximately half of the subjects in our study had a consistent asymmetrical deficit in muscle strength and power in the fractured limb. The other half of the participants either had no consistent strength deficit or had a strength deficit on the nonfractured side because of the more intense pain and higher burden of disease and injury affecting the nonfractured limb. Poor muscle strength in one lower limb may compromise mobility and balance; however, poor strength in both limbs may be more debilitating. The results of this study stress the importance of treating pain, disease, and injury affecting the lower limbs to prevent further decreases in muscle strength and power. Increasing muscle strength by intensive rehabilitation, including resistance training and pain management, may prevent or reduce limitations in mobility and balance that may lead to a loss of independence.

Erja Portegijs, $\mathrm{PhD}$

Taina Rantanen, $\mathrm{PhD}$
Ari Heinonen, $\mathrm{PhD}$

Department of Health Sciences,

University of Jyväskylä,

P.O. Box 35, FI-40014 Jyväskylä, Finland.

E-mail address for E. Portegijs: erja.portegijs@jyu.fi

Mauri Kallinen, MD, $\mathrm{PhD}$

GeroCenter Foundation for Research and Development,

Parantolantie 24, rak.1,

40930 Kinkomaa, Finland

Markku Alen, MD, PhD

Department of Medical Rehabilitation,

Oulu University Hospital,

P.O. Box 25,

90029 Oulu, Finland

Ilkka Kiviranta, $\mathrm{MD}, \mathrm{PhD}$

Department of Orthopaedics and Traumatology,

University of Helsinki,

Topeliuksenkatu 5 B,

00260 Helsinki, Finland

Sarianna Sipilä, $\mathrm{PhD}$

Finnish Centre for Interdisciplinary Gerontology,

University of Jyväskylä,

P.O. Box 3 (viv),

FL-40014 Jyväskylä, Finland

\section{References}

1. Kannus $P$, Sievänen $H$, Palvanen $M$, Järvinen $T$, Parkkari J. Prevention of falls and consequent injuries in elderly people. Lancet. 2005;366:1885-93.

2. Lauretani F, Russo CR, Bandinelli S, Bartali B, Cavazzini C, Di lorio A, Corsi AM, Rantanen T, Guralnik JM, Ferrucci L. Age-associated changes in skeletal muscles and their effect on mobility: an operational diagnosis of sarcopenia. J Appl Physiol. 2003;95:1851-60.

3. Rantanen T, Guralnik JM, Sakari-Rantala R, Leveille S, Simonsick EM, Ling $S$, Fried LP. Disability, physical activity, and muscle strength in older women: the Women's Health and Aging Study. Arch Phys Med Rehabil. 1999;80:130-5.

4. Tiainen K, Sipilä S, Alen M, Heikkinen E, Kaprio J, Koskenvuo M, Tolvanen A, Pajala S, Rantanen T. Shared genetic and environmental effects on strength and power in older female twins. Med Sci Sports Exerc. 2005;37:72-8.

5. Rantanen T, Era P, Heikkinen E. Physical activity and the changes in maximal isometric strength in men and women from the age of 75 to 80 years. J Am Geriatr Soc. 1997:45:1439-45.

6. Suetta C, Aagaard P, Magnusson SP, Andersen LL, Sipilä S, Rosted A, Jakobsen AK, Duus B, Kjaer M. Muscle size, neuromuscular activation, and rapid force characteristics in elderly men and women: effects of unilateral long-term disuse due to hip-osteoarthritis. J Appl Physiol. 2007;102:942-8.

7. Visser M, Simonsick EM, Colbert LH, Brach J, Rubin SM, Kritchevsky SB, Newman AB, Harris TB; for the Health ABC Study. Type and intensity of activity and risk of mobility limitation: the mediating role of muscle parameters. J Am Geriatr Soc. 2005;53:762-70.

8. Al Snih S, Raji MA, Peek MK, Ottenbacher KJ. Pain, lower-extremity muscle strength, and physical function among older Mexican Americans. Arch Phys Med Rehabil. 2005;86:1394-400.

9. Onder G, Cesari M, Russo A, Zamboni V, Bernabei R, Landi F. Association between daily pain and physical function among old-old adults living in the community: results from the iISIRENTE study. Pain. 2006;121:35-9.

10. O'Reilly SC, Jones A, Muir KR, Doherty M. Quadriceps weakness in knee osteoarthritis: the effect on pain and disability. Ann Rheum Dis. 1998;57: $588-94$.
11. Barker K, Lamb SE, Toye F, Jackson S, Barrington S. Association between radiographic joint space narrowing, function, pain and muscle power in severe osteoarthritis of the knee. Clin Rehabil. 2004;18:793-800.

12. Holder-Powell HM, Rutherford $O M$. Unilateral lower limb injury: its long-term effects on quadriceps, hamstring, and plantarflexor muscle strength. Arch Phys Med Rehabil. 1999;80:717-20.

13. Sherrington C, Lord SR. Increased prevalence of fall risk factors in older people following hip fracture. Gerontology. 1998;44:340-4.

14. Visser M, Harris TB, Fox KM, Hawkes W, Hebel JR, Yahiro JY, Michael R, Zimmerman SI, Magaziner J. Change in muscle mass and muscle strength after a hip fracture: relationship to mobility recovery. J Gerontol A Biol Sci Med Sci. 2000;55:M434-40.

15. Vlaeyen JW, Linton SJ. Fear-avoidance and its consequences in chronic musculoskeletal pain: a state of the art. Pain. 2000;85:317-32.

16. Lamoureux EL, Sparrow WA, Murphy A, Newton RU. Differences in the neuromuscular capacity and lean muscle tissue in old and older community-dwelling adults. J Gerontol A Biol Sci Med Sci. 2001;56:M381-5.

17. Lamb SE, Morse RE, Evans JG. Mobility after proximal femoral fracture: the relevance of leg extensor power, postural sway and other factors. Age Ageing. 1995;24:308-14.

18. Portegijs E, Sipilä S, Alen M, Kaprio J, Koskenvuo M, Tiainen K, Rantanen T. Leg extension power asymmetry and mobility limitation in healthy older women. Arch Phys Med Rehabil. 2005;86:1838-42.

19. Skelton DA, Kennedy J, Rutherford OM. Explosive power and asymmetry in leg muscle function in frequent fallers and non-fallers aged over 65. Age Ageing. 2002;31:119-25.

20. Portegijs E, Sipilä S, Pajala S, Lamb SE, Alen M, Kaprio J, Koskenvuo M, Rantanen T. Asymmetrical lower extremity power deficit as a risk factor for injurious falls in healthy older women. J Am Geriatr Soc. 2006;54:551-3.

21. Robertson S, Frost $\mathrm{H}$, Doll H, O'Connor JJ. Leg extensor power and quadriceps strength: an assessment of repeatability in patients with osteoarthritic knees. Clin Rehabil. 1998:12:120-6. 
The Journal of Bone \& Joint Surgery $\cdot$ JbJs.org VOLUME 91-A • NUMBeR 7 · July 2009
Lower-Limb Pain, Disease, and Injury Burden as Determinants of Muscle Strength Deficit After Hip Fracture
22. Steultiens MP, Dekker J, van Baar ME, Oostendorp RA, Bijlsma JW. Muscle strength, pain and disability in patients with osteoarthritis. Clin Rehabil. 2001;15:331-41.

23. Madsen OR, Lauridsen UB. Knee extensor and flexor strength in elderly women after recent hip fracture: assessment by the Cybex 6000 dynamometer of intrarater inter-test reliability. Scand J Rehabil Med. 1995;27:219-26.

24. Madsen OR, Lauridsen UB, Sørensen $\mathrm{OH}$. Quadriceps strength in women with a previous hip fracture: relationships to physical ability and bone mass. Scand J Rehabil Med. 2000;32:37-40.

25. van Wilgen $C P$, Akkerman $L$, Wieringa J, Dijkstra PU. Muscle strength in patients with chronic pain. Clin Rehabil. 2003;17:885-9.

26. Hannan EL, Magaziner J, Wang JJ, Eastwood EA, Silberzweig SB, Gilbert M, Morrison RS, McLaughlin MA, Orosz GM, Siu AL. Mortality and locomotion 6 months after hospitalization for hip fracture: risk factors and risk-adjusted hospital outcomes. JAMA. 2001;285:2736-42.

27. American College of Sports Medicine. ACSM's guidelines for exercise testing and prescription. 6th ed. Philadelphia: Lippincott Williams and Wilkins; 2000.

28. Sipilä S, Multanen J, Kallinen M, Era P, Suominen H. Effects of strength and endurance training on isometric muscle strength and walking speed in elderly women. Acta Physiol Scand. 1996;156:457-64.

29. Bassey EJ, Short AH. A new method for measuring power output in a single leg extension: feasibility, reliability and validity. Eur J Appl Physiol Occup Physiol. 1990;60:385-90.

30. Völgyi E, Tylavsky FA, Lyytikäinen A, Suominen H, Alén M, Cheng S. Assessing body composition with DXA and bioimpedance: effects of obesity, physical activity, and age. Obesity. 2008;16:700-5.
31. Dipietro L, Caspersen CJ, Ostfeld AM, Nadel ER. A survey for assessing physical activity among older adults. Med Sci Sports Exerc. 1993;25:628-42.

32. Heuts PH, Vlaeyen JW, Roelofs J, de Bie RA, Aretz K, van Weel C, van Schayck OC. Pain-related fear and daily functioning in patients with osteoarthritis. Pain. 2004;110:228-35.

33. Delbaere K, Crombez G, Vanderstraeten G, Willems T, Cambier D. Fear-related avoidance of activities, falls and physical frailty. A prospective community-based cohort study. Age Ageing. 2004;33:368-73.

34. Herrick C, Steger-May K, Sinacore DR, Brown M, Schechtman KB, Binder EF. Persistent pain in frail older adults after hip fracture repair. J Am Geriatr Soc. 2004;52:2062-8.

35. Topp R, Woolley S, Hornyak J 3rd, Khuder S, Kahaleh B. The effect of dynamic versus isometric resistance training on pain and functioning among adults with osteoarthritis of the knee. Arch Phys Med Rehabil. 2002;83:1187-95.

36. Fiatarone MA, O'Neill EF, Ryan ND, Clements KM, Solares GR, Nelson ME, Roberts SB, Kehayias JJ, Lipsitz LA, Evans WJ. Exercise training and nutritional supplementation for physical frailty in very elderly people. N Eng J Med. 1994:330:1769-75.

37. Suetta C, Magnusson SP, Rosted A, Aagaard P, Jakobsen AK, Larsen LH, Duus $\mathrm{B}$, Kjaer M. Resistance training in the early postoperative phase reduces hospitalization and leads to muscle hypertrophy in elderly hip surgery patients - a controlled, randomized study. J Am Geriatr Soc. 2004;52:2016-22.

38. Mitchell SL, Stott DJ, Martin BJ, Grant SJ. Randomized controlled trial of quadriceps training after proximal femoral fracture. Clin Rehabil. 2001;15:282-90.

39. Binder EF, Brown M, Sinacore DR, Steger-May K, Yarasheski KE, Schechtman KB. Effects of extended outpatient rehabilitation after hip fracture: a randomized controlled trial. JAMA. 2004;292:837-46. 